\title{
Challenges and Role Changes in Caring for Adult Children With Cancer
}

\author{
LAURA BOURDEANU, NP, PhD, and PATRICIA CANNISTRACI, DSN, RN, CNE
}

From Excelsior College, Albany, New York

Authors' disclosures of conflicts of interest are found at the end of this article.

Correspondence to: Laura Bourdeanu, NP, PhD, Excelsior College, 7 Columbia Circle, Albany, NY 12203. E-mail: Ibourdeanu@vahoo.com

https://doi.org/10.6004/jadpro.2018.9.6.5

(c) 2018 Harborside $^{\text {TM }}$

\section{CASE STUDY}

Here we present a case of a mother's struggle, in her own words, about defining her new role after her adult son's cancer diagnosis and the importance of practicing family-centered care in this scenario.

\section{A Mother's Role}

At 27 years old, my son, Stephan, received a diagnosis of testicular embryonal carcinoma with metastatic retroperitoneal adenopathy. The standard treatment recommended by the guidelines included surgery and chemotherapy. It's different when your child of young adult age is diagnosed with cancer. The dreaded words of "It's cancer" were challenging for me to hear as his mother. But those limbo years when your child is not really a child any longer add to the challenge. They are old enough to be in college or to have completed college, yet they are not fully independent and perhaps not married or with a family of their own yet. Levinson (1976) labeled this 20- to 39-year-old age range as "provisional adult," while Havighurst (1956) used the terms "young adult" or "early adulthood." As a nurse, I use these labels myself to describe these patients. However, labels cannot change the ambiguous nature of your role as you care for your young adult child who has a cancer diagnosis.

Stephan had achieved many common milestones set by sociologists that serve as benchmarks in the transition to adulthood: $\mathrm{He}$ achieved a degree, left his childhood home, was financially independent, and was in a long-term relationship. His diagnosis seemed to make the world stop. His independence was replaced with agendas designed by various health-care providers: appointments that included ultrasounds, labs, meetings with specialists, surgery, chest port insertion, and chemotherapy treatments. My role in supporting his independence changed, too. I suddenly felt unscripted for the journey of this experience.

\section{Family Strategies}

A sense of ambiguity pervaded our lives. Initially, health-care providers used words such as "cancer," "aggressive," and "tumor," and they weighed heavily in our hearts. We also heard words of hope, such as "cure," and "95\%." Stephan had to make decisions that were uncom- 
mon for people of his age to make about a prosthetic device, chemotherapy agents, and length of treatment. Fundamental to all this turmoil, though, was hope. Providers spoke of hope. Early on, I decided our family unit would need to focus on this to keep hope alive in my son's world. During the long and low days ahead and during times when exhaustion prevailed, we conscientiously reminded each other of hope and kept that thought illuminated in my son's world.

Early on in Stephan's journey, I realized that being present in the moment helped him to be calm, rally strength, and sometimes even develop a sense of control. I encouraged our family to be considerate of being present by disengaging from technology and just being in the moment with my son, allowing his priorities to become our priorities. This went beyond sitting with him during chemotherapy infusion; it expanded into time off for his girlfriend so she could also relax and take a break. To do this, we needed to be honest with each other without judgment. If his girlfriend needed a break one evening, I could be there to give her that relief.

It became apparent as the weeks of treatment turned into months that our ability to be present was facilitated by communication. My son's girlfriend and I promised one another to be open and honest in our communication. As his mother, I just wanted to be by his side, caring, cooking, and assuring his comfort. Those instinctive urges are powerful yet not realistic. My son's girlfriend and I openly discussed ways I could help: sending over a few meals, assuming responsibility for transportation to and from chemotherapy on certain days, and being the key person to keep extended family informed. I was surprised at how quickly our honest communication became a well-oiled machine of support for my son and their home life.

After the last round of chemotherapy was completed, I began to reflect on how we had made it through the 4-month journey and how I was able to support my son, honoring his independence as a young adult and honoring my role as mother of a young adult with cancer. I only had one word: courage. For lack of a better explanation, I define courage as being willing and able to show up each day, face the challenges no matter how good or bad, and see the day through to the end. It takes a healthy dose of courage to be part of the support team for a loved one facing cancer treatments. The staff who cared for my son were all excellent, supportive, and informative. But they stopped short of acknowledging the uniqueness of the parent-young adult roles. I had to find my voice and design a new role that was important to me as his mother. This was vital for me and for my son. I will never stop being his mother, nor he my son.

ancer affects over 60,000 young adults aged 20 to 39 each year (Fidler et al., 2017). Although uncommon, caring for young adults with cancer requires addressing their unique and specific concerns. Young adulthood is a time of great change in a person's life as he/she tries to establish an identity and develop social, emotional, and financial independence. It is also a challenging time for parents, as their role needs to evolve from that of a nurturer, advisor, and protector, to viewing their grown children as independent beings who are living independent lives. This time becomes more challenging when the young adult child receives a diagnosis of a serious illness (James, Andershed, \& Ternestedt, 2007; Van Humbeeck et al., 2015). Despite the fact that these patients are no longer under the care of their parents, family-centered care should still be employed, as studies have found that patients' outcomes improve with its utilization (American Hospital Association, 2017; Goldfarb, Bibas, Bartlett, Jones, \& Khan, 2017). In order to successfully implement family-centered care in this setting, advanced practitioners must first understand that the subtleties of the relationship between parent and adult child can be quite distressing in this scenario, as parents are faced with decisions about how involved they should be in their adult child's life.

\section{IMPACT OF A CANCER DIAGNOSIS ON PARENTS}

The impact of an adult child's cancer diagnosis on the parent is unlike cancer experiences at other stages of life. Parents face many challenges, not the least of which is renegotiating their relationship with their adult child. At this stage, parents of adult children have moved from being responsible for the health and welfare of their child to that of allowing their child to make their own indepen- 
dent health-related decisions. A cancer diagnosis clearly presents a challenge for parents who have attempted to facilitate the child's independence and now experience the desire to nurture and protect their child as if he/she were a minor, creating a state of confusion for them (Grinyer, 2008). Parents are forced to transform their role into one of the caretaker while accepting their child's autonomy. The ease of the role transformation depends heavily on the parents' working status or social relationships, the child's marital or relationship status, the parents' relationship with the child's significant other, the quality of child-parent communication, and information about their child's illness (Kelly \& Gibson, 2008).

\section{PARENTAL ROLE \\ Initial Feelings}

Parents instinctively view themselves as the child's protectors. However, most recognize that they cannot care for a sick adult child in the same way they would care for a sick minor. As a result, they experience a multitude of intense feelings. They are completely preoccupied with their adult child's diagnosis, while experiencing uncertainty and helplessness (Dean, McClement, Bond, Daeninck, \& Nelson, 2005; Raveis, Pretter, \& Carrero, 2010). Contributing to the sense of helplessness is the parents' perception of their child's suffering and their own sense of incapacity and insufficiency. Parents want to play an active role in their child's treatment but feel they lack the skills to stop the child's suffering (Persson \& Sundin, 2008). Parents are also experiencing their own emotional suffering as they struggle to find a cause for the child's condition, deal with a sense of injustice as they themselves are being spared of the disease, or search for the existence of self-blame (Raveis et al., 2010).

\section{Honoring Autonomy and Independence}

By virtue of their age, adult children are considered independent and autonomous patients. This independence and autonomy may be problematic for parents, as the role of the parent is an enduring one. The parents' need to assist their child or take control may clash with the principle of honoring the child's autonomy. This issue is further complicated if their child has to relinquish their independence and autonomy and move in with his/her parents. Parents may experience difficulty in allowing their child the freedom to maintain or regain their independence (Grinyer, 2009), as they may perceive some of the child's risky behaviors as exacerbating his/her illness. Their instinct is to protect their child and maximize the chance of survival. The new dependence of the child on the parent may also be problematic for parents who have established new relationships or routines since their child moved away from home, leading to tensions between parents and young adults (Grinyer, 2002)

\section{Loss of Control}

Parents of young adults with cancer are faced with having little opportunity to influence the choices of their children. Moreover, they no longer have the right to be informed. They have to rely on obtaining information through their child or their child's partner. This uncertainty about the course of the disease and the treatment effects on their child lead to feelings of helplessness and frustration (Raveis et al., 2010). As they now lack legitimate reason to be involved in the decision-making process, and their child is now a self-sufficient adult, parents have to be careful with how they ask their child questions about their disease and treatment outcomes (Grinyer, 2012).

Further loss of control and conflicting emotions are experienced by the parents when the adult child has a partner or spouse. While the partner or spouse takes on the role of the primary caregiver, parents, with their innate need to be the child's caretaker, may feel marginalized or excluded in these circumstances (Grinyer, 2012). In these cases, roles and relationships must be negotiated with sensitivity by both parties, as role changes can have a negative impact on the patient's emotional well-being.

\section{SHARED DECISION-MAKING}

Family members play an important role when decisions about cancer care are being made and, in most cases, they serve as the caretakers. Patients may rely on their family members not only for physical and emotional support, but also for their input on the treatment recommendations. Studies show that nearly half of patients diagnosed with cancer involve family members in their treatment 
decisions (Hobbs et al., 2015). In addition, studies suggest that family involvement in the decision-making process is associated with improved outcomes, patient satisfaction, and treatment adherence (Wolff \& Roter, 2008). However, contemporary bioethics place an emphasis on patient autonomy and confidentiality. As family members become more involved in the decision-making process, they view themselves as partners with the physician in the care of the patient (Glasser, Prohaska, \& Gravdal, 2001). In these situations, there is a risk that communication about the patient's treatment will shift to the family member, which is in violation of the current bioethics laws. Given the importance of the family members in the care and decision-making process, health-care providers must recognize the need for a family-centered approach, all while maintaining the dignity and autonomy of their patients.

\section{FAMILY-CENTERED CARE}

Young adults with cancer require complex care delivered with the ongoing involvement of oncologists or hematologists. This type of care requires a team approach that includes not only the patient and the health-care team, but also the patient's family. This type of care, termed family-centered care, recognizes the importance of the family in the patient's life. Its goal is to create partnerships among health-care practitioners, patients, and families that will lead to the best outcomes and enhance the quality and safety of health care (American Hospital Association, 2017). There are four principles that guide family-centered care: dignity and respect, information sharing, participation, and collaboration.

\section{Dignity and Respect}

Treating patients and families with respect entails listening to and honoring their perspectives and choices. Decisions regarding treatment should be based on patient and family knowledge about cancer and incorporate their values, beliefs, and cultural background (American Hospital Association, 2017; Mazanec, Flocke, \& Daly, 2015).

\section{Information Sharing}

The exchange of information among patients, doctors, and family members should be open, ob- jective, and unbiased. All team members must receive timely, complete, and accurate information during the entire care process (American Hospital Association, 2017).

\section{Participation}

Patients and their families should be encouraged to participate in making care decisions during treatment. Participation will lead to determining medically appropriate decisions that best fit the needs, strengths, values, and abilities of the patient (American Hospital Association, 2017).

\section{Collaboration}

Patients, families, health-care providers, and leadership at institutions should work together to develop policies, programs, and evaluation strategies that make patient care delivery services more effective. Patients and family members should be encouraged to participate in advisory councils that shape hospital policies and practices. Without their participation, the health-care system may fail to respond to the real needs of patients (American Health Association, 2017).

\section{IMPLICATIONS FOR PRACTICE}

As this case study highlights, family-centered care needs to address the gap created when a young adult is diagnosed with cancer. The four principles that guide family-centered care are undoubtedly important and contribute to best practices. Family-centered care has a direction of flow toward the patient, achieving positive outcomes. However, this may necessitate reflection on roles and relationships within the family unit. This can be achieved by knowing-in-action or reflection on practice on the part of healthcare providers.

Parents of young adults may exhibit a high degree of emotional pain, feel a sense of injustice, and experience a loss of control. Alleviating these feelings comes through the empowering of parents to seek roles that allow them to still parent while honoring the young adult's independence. Defining the parenting role will require practitioners to engage in conversation about the ambiguity of the situation. Assisting parents in exploring their feelings can inspire them to feel less helpless and more enabled. 


\section{CONCLUSION}

Family-centered care is an important and necessary element of cancer care. In order to successfully integrate family-centered care into the cancer care of a young adult, the advanced practitioner must first acknowledge and understand the parents' roles in the patient's life and potentially empower the parents to redefine their role in order to better assist with the care of their child. Given the benefits of family-centered care, oncology and hematology advanced practitioners should embrace this philosophy and incorporate it into their daily practice and in all appropriate standards and policies for cancer care.

\section{Dedication}

This article is dedicated to Stephan, a young man whose desire to survive and overcome adversity has carried him through a second occurrence of testicular cancer. May practitioners embrace a family-centered approach to care, regardless of the patient's age.

\section{Disclosure}

The authors have no conflicts of interest to disclose.

\section{References}

American Hospital Association. (2017). Strategies for leadership: Patient- and family- centered care. Retrieved from https://www.aha.org/toolkitsmethodology/201802-08-patient-and-family-centered-care-hospital-selfassessment-inventory

Dean, M., McClement, S., Bond, J. B., Jr., Daeninck, P. J., \& Nelson, F. (2005). Parental experiences of adult child death from cancer. Journal of Palliative Medicine, 8(4), 751-765. https://doi.org/10.1089/jpm.2005.8.751

Fidler, M. M., Gupta, S., Soerjomataram, I., Ferlay, J., Steliarova-Foucher, E., \& Bray, F. (2017). Cancer incidence and mortality among young adults aged 20-39 years worldwide in 2012: A population-based study. Lancet Oncology, 18(12), 1579-1589. https://doi.org/10.1016/S14702045(17)30677-0

Glasser, M., Prohaska, T., \& Gravdal, J. (2001). Elderly patients and their accompanying caregivers on medical visits. Research on Aging, 23(3), 326-348. https://doi. org/10.1177/0164027501233003

Goldfarb, M. J., Bibas, L., Bartlett, V., Jones, H., \& Khan, N. (2017). Outcomes of patient- and family-centered care interventions in the ICU: A systematic review and meta-analysis. Critical Care Medicine, 45(10), 1751-1761. https://doi.org/10.1097/CCM.0000000000002624
Grinyer, A. (2002). Cancer in young adults: Through parents' eyes. Buckingham: Open University Press.

Grinyer, A. (2008). The impact of cancer on parents of adolescents and young people. In D. Kelly \& F. Gibson (Eds.), Cancer care for adolescents and young adults (pp. 44-58). Oxford: Blackwell. https://doi. org/10.1002/9780470697740.ch3

Grinyer, A. (2009). Contrasting parental perspectives with those of teenagers and young adults with cancer: Comparing the findings from two qualitative studies. European Journal of Oncology Nursing, 13(3), 200-206. https:// doi.org/10.1016/j.ejon.2009.04.002

Grinyer, A. (2012). A bereavement group for parents whose son or daughter died from cancer: How shared experience can lessen isolation. Mortality, 17(4), 338-354. https://doi.org/10.1080/13576275.2012.730684

Havighurst, R. J. (1956). Research on the developmental-task concept. School Review, 64(5), 215-223. Retrieved from https://www.jstor.org/stable/1083328

Hobbs, G. S., Landrum, M. B., Arora, N. K., Malin, J., Ganz, P. A., van Ryn, M.,...Keating, N. L. (2015). The role of families in decisions about cancer treatments. Journal of Clinical Oncology, 121(7), 1079-1087. https://dx.doi. org/10.1002\%2Fcncr.29064

James, I., Andershed, B., \& Ternestedt, B. M. (2007). A family's beliefs about cancer, dying, and death in the end of life. Journal of Family Nursing, 13(2), 226-252. https:// doi.org/10.1177/1074840707300849

Kelly, D., \& Gibson, F. (Eds.). (2008). Cancer care for adolescents and young adults. Blackwell Publishing Ltd: Malden, MA. https://doi.org/10.1002/9780470697740

Levinson, D. (1976). Periods in adult development of men: Ages 18 to 45. Counseling Psychologist, 6(1), 21-25. https:// doi.org/10.1177/001100007600600105

Mazanec, S. R., Flocke, S. A., \& Daly, B. J. (2015). Health behaviors in family members of patients completing cancer treatment. Oncology Nursing Forum, 42(1), 54-62. https://doi.org/10.1188/15.ONF.54-62

Persson, C., \& Sundin, K. (2008). Being in the situation of a significant other to a person with inoperable lung cancer. Cancer Nursing, 31(5), 380-388. https://doi. org/10.1097/01.NCC.0000305763.89109.60

Raveis, V. H., Pretter, S., \& Carrero, M. (2010). 'It should have been happening to me': The psychosocial issues older caregiving mothers experience. Journal of Family Social Work, 13(2), 131-148. https://doi. org/10.1080/10522150903503002

Van Humbeeck, L., Dillen, L., Piers, R., Deveugele, M., Grypdonck, M., Verhaeghe, S., \& Van Den Noortgate, N. (2015). Tightrope walkers suffering in silence: A qualitative study into the experiences of older parents who have an adult child with cancer. International Journal of Nursing Studies, 52(9), 1445-1453. https://doi.org/10.1016/j. ijnurstu.2015.05.010

Wolff, J. L., \& Roter, D. L. (2008). Hidden in plain sight: Medical visit companions as a resource for vulnerable older adults. Archives of Internal Medicine, 168(13), 1409-1415. https://doi.org/10.1001/archinte.168.13.1409 